\title{
Nebulized Heparin for Post-COVID-19-Related Hypoxia
}

\author{
Mehmet Hursitoglu10 ${ }^{10}$ Erhan Eroz ${ }^{1}$ Mehmet Akif Ozgul ${ }^{2}$ \\ 1 Internal Medicine Department, Basaksehir Cam \& Sakura Sehir \\ Hospital, University of Health Sciences, Istanbul, Turkey \\ 2 Pulmonary Medicine and Interventional Pulmonology Department, \\ Basaksehir Cam and Sakura Sehir Hospital, University of Health \\ Sciences, Istanbul, Turkey \\ Address for correspondence Mehmet Hursitoglu, MD, Internal \\ Medicine Department, Basaksehir Cam \& Sakura Sehir Hospital, \\ University of Health Sciences, Basaksehir mahallesi G-434 Caddesi No. \\ 2L, Basaksehir, Istanbul 34100, Turkey \\ (e-mail: hursitoglum@yahoo.com).
}

TH Open 2021;5:e312-e314.

To the editor

The pulmonary manifestations of coronavirus disease 2019 (COVID-19) may require a long time follow-up and a special therapeutic approach (such as pulmonary rehabilitation, supplementary oxygens, etc.). ${ }^{1-3}$ This may end with pulmonary fibrosis that necessitates long time oxygen therapy. ${ }^{4}$ Most of these patients are hospitalized because of oxygen supply need that exceeds the capacity of portable or home oxygen concentrator devices. ${ }^{5}$ Nebulized and/or inhaled unfractionated heparin is investigated in some disease conditions. Some examples of these are smoke inhalation-related lung injuries, adult respiratory distress syndrome (ARDS), and pulmonary fibrosis. These trials were all safe and successful somewhat. ${ }^{6-8}$ Here, we report two cases of post-COVID-19-related disabling respiratory distress conditions that were treated with nebulized unfractionated heparin administration.

The first case was that of an 81-year-old female COVID-19 patient. She was admitted to our hospital's intensive care unit (ICU) for mechanical ventilation support. A three day pulse $250 \mathrm{mg}$ and $80 \mathrm{mg}$ maintenance dose of IV methylprednisolone was started. Also, she had received diuretics and different antibiotics. After 24 days of ICU unit care, she has been transmitted to our medical world with a $10 \mathrm{~L} \mathrm{O}_{2}$ supply using a non-rebreather (NRB) facemask. Her ICU maintenance treatment of subcutaneous low molecular weight heparin (LMWH) enoxaparin sodium $0.6 \mathrm{~mL}$ twice daily, methylprednisolone $40 \mathrm{mg}$ PO daily continued. During her seventh day of follow-up at our medical ward, $\mathrm{N}$-acetylcysteine $300 \mathrm{mg}$ IV thrice daily was also initiated. Despite these maintenance therapies, her $\mathrm{O}_{2}$ need was not decreased. On the 14th day of medical ward follow-up, still, her $\mathrm{O}_{2}$ requirement was 8 to $10 \mathrm{~L}$ (to keep pulse oxymetry oxygen saturation $\left[\mathrm{sO}_{2}\right]$ at $\left.92 \%\right)$. The ground glass appearances,

received

May 4, 2021

accepted after revision

June 16, 2021 bronchial dilatations, and cardiomegaly are evident in her chest CT (-Fig. 1). Her insistence on home discharge was continued even at this critical level of $\mathrm{O}_{2}$ supply need. After a thorough search for possible nonharmful therapeutic approaches at these conditions, the suggestion of using nebulized heparin was made by the first author. In addition to the COVID-19 inpatient written consent form, this treatment was discussed with the patient and her first-degree kin. After a positive response, the first dose of $10,000 \mathrm{IU}$ UFH (Koparin [Kocak Farma Ltd. Co.]) was administered by nebulizer for 1 hour (diluted in $3 \mathrm{~mL}$ of $0.9 \% \mathrm{NaCl}$ solution). At the next day of this treatment, her oxygen need was decreased to $5 \mathrm{~L}$ ( $\mathrm{sO}_{2}$ was $92 \%$ ) (without any noted side effects). So, the dose of nebulized UFH increased to twice daily thereafter. At the end of third day of nebulized UFH treatment, her $\mathrm{sO}_{2}$ became $94 \%$ (with only a $4 \mathrm{~L}$ nasal $\mathrm{O}_{2}$ supply). Because of her insistence, she was discharged home with a portable $\mathrm{O}_{2}$ concentrator treatment support. On the 10th day of discharge, she has contacted by phone. She claimed that she is doing well. $\mathrm{Her} \mathrm{SO}_{2}$ is approximately $95 \%$ (with a $3-4 \mathrm{~L} \mathrm{O}_{2}$ supply) (-Table 1 for the progress).

The second case was that of a 67-year-old male COVID-19 patient. His chest CT shows consolidations, ground-glass appearance, and bronchial dilations (-Fig. 1). On the 17th day of admission, NRB facemask $\mathrm{O}_{2}$ support was not successful in keeping his $\mathrm{sO}_{2}$ levels above $92 \%$. So, heated and humidified high-flow nasal oxygen support was started. Supportive maintenance steroid and LMWH were all given. On the 29th day of hospital admission, $\mathrm{O}_{2}$ needs were settled at $10 \mathrm{~L}$ (with $\mathrm{sO}_{2}$ levels of $90-91 \%$ ). With the courage of positive results of our nebulized UFH therapy in the above first case, we discussed this treatment option with this patient too. After a positive response, as in the above previous patient, this UFH treatment was initiated as $10,000 \mathrm{IU}$

\section{(c) 2021. The Author(s).}

This is an open access article published by Thieme under the terms of the Creative Commons Attribution License, permitting unrestricted use, distribution, and reproduction so long as the original work is properly cited. (https://creativecommons.org/licenses/by/4.0/) Georg Thieme Verlag KG, Rüdigerstraße 14, 70469 Stuttgart, Germany 

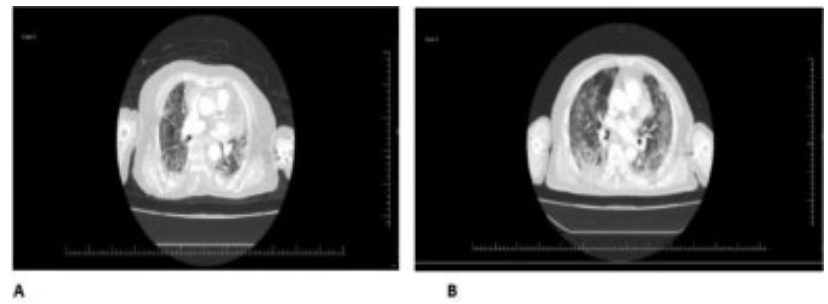

Fig. 1 Views from chest computed tomography of the cases $(A=$ Case 1 , and $\mathbf{B}=$ Case 2).

twice daily. On the day of starting this treatment, the $\mathrm{sO}_{2}$ level was $91 \%$ (with a $10 \mathrm{~L}$ NRB facemask $\mathrm{O}_{2}$ supply). The day after starting this therapy, his $\mathrm{sO}_{2}$ was raised to $93 \%$ (with an $8 \mathrm{~L} \mathrm{O}_{2}$ supply). As in the first case, this patient was discharged on the fifth day of completion of UFH therapy with a 2 to $3 \mathrm{~L}$ $\mathrm{O}_{2}$ supply need only $\left(\mathrm{sO}_{2}=94 \%\right)(-$ Table 1$)$.

\section{Discussion}

Autopsy studies in COVID-19 showed that the rate of pulmonary fibrosis increase with the duration of the disease in ARDS patients. These fibrosis detection rates were 4 , 24 , and $61 \%$ in $<1$ week, 1 to 3 weeks, and $>3$ weeks, respectively. The pulmonary route of administration of heparin is tried in some types of respiratory diseases and non-COVID-19 related ARDS conditions before. There are no reports of major (or even minor) even with a maximum 120,000 IU unfractionated heparin per day. ${ }^{6-8}$ The main reason for the long-time hospital stay of our first case was the high need for $\mathrm{O}_{2}(10 \mathrm{~L})$. So, after informing the patient about nebulized UFH trials, she accepted our suggestion. On first day, only a single dose of UFH 10,000 IU was tried. The next day, a dramatic decrease in $\mathrm{O}_{2}$ need was observed. So, a twice daily 10,000 IU of nebulized heparin was continued later. In our patients series, the absolute eosinophil count of severe critically ill COVID-19 patients is so low (mostly zero) (unpublished data). Experimental studies showed that heparin inhibits allergen-induced eosinophil infiltration into the lung by a mechanism other than its anticoagulant activity. ${ }^{9}$ As we know, cytotoxic eosinophil granule proteins are implicated in the pathogenesis of some airway diseases. The protective activity of heparin may be related to its local effect of neutralization of eosinophil cationic protein. ${ }^{10}$ This may explain partially the obvious effect of nebulized UFH on improving $\mathrm{sO}_{2}$ levels of both cases that the parenteral heparin failed to show such effect. But we should mention that heparin has antiviral, anti-inflammatory, and mucolytic effects as well. ${ }^{11}$ This easy and cheap seemly effective treatment model needs to be pointed out in future studies. Its safety and usefulness were also confirmed at the early phase of COVID-19 infection. ${ }^{12}$ Using such cheap and safe drugs during such challenging pandemic and a global risk of economic crises is of paramount importance (even in developed countries). So, it seems that nebulized UFH treatment is safe and effective in reducing $\mathrm{O}_{2}$ need at

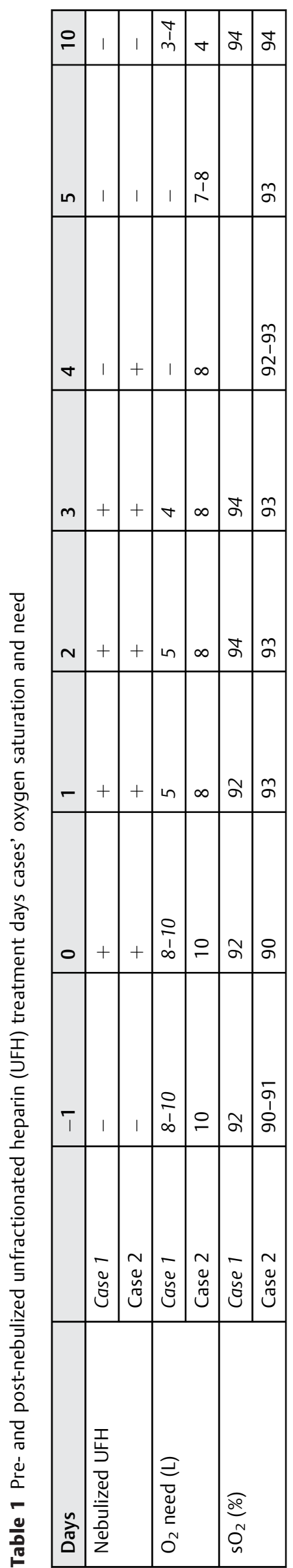


long-standing COVID-19-related hypoxia. Still, further studies are needed to confirm this.

\section{Conflict of Interest}

None declared.

\section{References}

1 Greenhalgh T, Knight M, A'Court C, Buxton M, Husain L. Management of post-acute COVID-19 in primary care. BMJ 2020;370:m3026

2 van de Veerdonk FL, Kouijzer IJE, de Nooijer AH, et al. Outcomes associated with use of a Kinin B2 receptor antagonist among patients with COVID-19. JAMA Netw Open 2020;3(08):e2017708

3 Recognizing happy hypoxia syndrome as a new symptom of COVID-19 | Universitas Gadjah Mada. Access December 20, 2020 at: https://www.ugm.ac.id/en/news/19993-recognizinghappy-hypoxia-syndrome-as-a-new-symptom-of-covid-19

4 Rai DK, Sharma P, Kumar R. Post COVID-19 pulmonary fibrosis. Is it real threat? Indian J Tuberc 2021;68(03):330-333

5 Sardesai I, Grover J, Garg M, et al. Short term home oxygen therapy COVID-19 patients: the COVID-HOT algorithm. J Family Med Prim Care 2020;9(07):3209-3219

6 Yildiz-Pekoz A, Ozsoy Y. Inhaled heparin: therapeutic efficacy and recent formulations. J Aerosol Med Pulm Drug Deliv 2017;30(03):143-156
7 Ashraf U, Bajantri B, Roa-Gomez G, Venkatram S, Cantin A, DiazFuentes G. Nebulized heparin and N-acetylcysteine for smoke inhalational injury: a case report. Medicine (Baltimore) 2018;97 (19):e0638

8 Abdelaal Ahmed Mahmoud A, Mahmoud HE, Mahran MA, Khaled $M$. Streptokinase versus unfractionated heparin nebulization in patients with severe acute respiratory distress syndrome (ARDS): a randomized controlled trial with observational controls. J Cardiothorac Vasc Anesth 2020;34(02):436-443

9 Seeds EAM, Page CP. Heparin inhibits allergen-induced eosinophil infiltration into guinea-pig lung via a mechanism unrelated to its anticoagulant activity. Pulm Pharmacol Ther 2001;14(02):111-119

10 Vancheri C, Mastruzzo C, Armato F, et al. Intranasal heparin reduces eosinophil recruitment after nasal allergen challenge in patients with allergic rhinitis. J Allergy Clin Immunol 2001;108 (05):703-708

11 van Haren FMP, Page C, Laffey JG, et al. Nebulised heparin as a treatment for COVID-19: scientific rationale and a call for randomised evidence. Crit Care 24 454;2020https://doi.org/10.1186/ s13054-020-03148-2

12 Dixon B, Smith RJ, Campbell DJ, et al; CHARLI Study Group. Nebulised heparin for patients with or at risk of acute respiratory distress syndrome: a multicentre, randomised, double-blind, placebo-controlled phase 3 trial. Lancet Respir Med 2021;9(04): 360-372 